\title{
UJI PERFORMANSI DAN EMISI GAS BUANG MESIN DIESEL PERKIN 4 SILINDER KAPASITAS 75 KW BERBAHAN BAKAR ECOLU
}

\author{
Ika Yuliyani, Kartono dan Indah P. \\ Jurusan Teknik Konversi Energi - Politeknik Negeri Bandung \\ Ikyu_andi03@yahoo.co.id
}

\begin{abstract}
Abstrak
Ecopro adalah suatu alat yang dikembangkan untuk mengubah minyak nabati atau minyak goreng bekas menjadi ecolu yang dapat digunakan sebagai bahan bakar mesin diesel. Hasil uji karakteristik menunjukkan bahwa ecolu dari minyak jelantah memiliki angka setan, densitas, dan flash point yang lebih tinggi dibandingkan dengan solar. Selain itu ecolu juga merupakan bahan bakar yang ramah lingkungan karena tidak mengandung belerang. Sedangkan kekurangan ecolu adalah memiliki viskositas yang cukup kental sehingga mudah menyumbat pada saluran pompa injeksi. Hasil pengujian pada mesin diesel Perkin 75 KVA di laboratorium Teknik Konversi Energi POLBAN pada putaran 1400 - 2775 rpm, menunjukkan bahwa emisi gas bwang ecolu lebih ramah lingkungan, akan tetapi performansi mesin diesel berbahan bakar ecolu lebih rendah dibandingkan solar karena ecolu memiliki nilai kalor yang lebih rendah dibanding solar.
\end{abstract}

Katak kunci: ecolu, mesin diesel, performansi, emisi gas buang.

\section{PENDAHULUAN}

Penggunaan minyak nabati sebagai bahan bakar mesin diesel sudah mulai diprakarsai oleh Dr. Rudolf Diesel pada pameran internasional tahun 1900 di Paris. Namun dalam perkembangannya, minyak bumi sebagai bahan bakar merupakan pilihan yang utama karena pada saat itu harganya murah dan mudah didapat. Baru pada saat-saat sekarang ketika harga minyak bumi semakin mahal yang pada tahun 2008 pernah mencapai 100 US\$ per barel, orang mulai melirik kembali penggunaan minyak nabati sebagai bahan bakar alternatif. Selain itu, pengolahan untuk pemanfaatan dari minyak goreng bekas sebagai bahan bakar juga mulai

Ecolu merupakan bahan bakar alternatif yang dibuat dari minyak nabati atau minyak goreng bekas yang dicampur dengan bahan bakar lain seperti light oil, heavy oil atau minyak tanah, yang selanjutnya diolah dengan menggunakan mesin Ecopro. Hasil proses pengolahan mesin ecopro tersebut menghasilkan bahan bakar baru yång disebut ecolu yang sifatnya lebih bersih, lebih ramah lingkungan dan mempunyai efisiensi pembakaran yang tinggi (Seiki H., 2001).
Karakteristik ecolu mirip dengan minyak solar sehingga ecolu memungkinkan untuk dapat digunakan sebagai bahan bakar alternatif pada mesin diesel, baik dalam bentuk campuran ecolu -minyak solar ataupun dalam bentuk ecolu murni. Bahkan ecolu mempunyai keunggulan dibanding minyak ${ }^{\bullet}$ solar yaitu mempunyai bilangan setana yang lebih tinggi dan mempunyai kadar belerang yang lebih rendah, sehingga proses pembakaran ecolu menjadi lebih baik dan menghasilkan gas buang yang lebih ramah lingkungan. Sebagai perbandingan: solar yang dicampur biodiesel dapat mempunyai bilangan setana hingga 64 , pertamina DEX (diesel environment extra) mempunyai bilangan setana 53 , sedangkan minyak solar memberikan mempunyai bilangan setana 48 (Syarief E., 2004).

Hanya viskositas ecolu lebih kental dibanding minyak solar sehingga lebih mudah untuk terjadinya penyumbatan pada saluran pipa, saringan dan terutama pada nozzle. Proses pembakaran juga dapat terhambat dan memungkinkan terjadinya endapan karbon pada ujung penyembur minyak. Salah satu cara untuk mengatasi kesulitan-kesulitan tersebut adalah dengan terlebih dulu memanaskan minyak, saluran dan saringan sebelum dilakukan proses pembakaran mesin diesel 
Pengujian karakteristik ecolu dan performansinya pada mesin diesel belum banyak dilakukan orang, sehingga pada penelitian ini untuk melakukan uji karakteristik yang meliputi: nilai kalor, viskositas kandungan belerang, dan bilangan setana, serta uji performansi pada mesin diesel dengan parameter-parameter yang diuji meliputi: daya poros, konsumsi bahan bakar spesifik dan effisiensi mekanik. Di samping itu juga uji emisi gas buang yang meliputi: HC, $\mathrm{CO}, \mathrm{CO}_{2}$ dan asap. Pengujian akan dilakukan dengan menggunakan mesin diesel statis merk perkin 4 silinder dengan kapasitas $75 \mathrm{KW}$ yang ada di Laboratorium Jurusan Teknik Konversi Energi POLBAN.

\section{METODOLOGI}

Metodologi penelitian yang digunakan pada kegiatan ini meliputi:

1. Pengujian karakteristik ecolu dan solar, yang meliputi karakteristik fisik dan kimia. Pengujian ini dilakukan oleh PT. Bumi Energy Equatorial (BEE) yaitu perusahaan yang memproduksi ecolu. Karakteristik yang diuji meliputi: angka setana, densitas, kandungan sulfur, kandungan sulfat dalam abu, flash point dan LHV.

2. Pengujian . performansi mesin, dengan beberapa metode pengujian, yaitu:

- Pengujian dengan pengaturan katup aliran gas

- Pengujian dengan pengaturan beban

- Pengujian dengan pengaturan kecepatan putaran

Kegiatan ini dilakukan di Laboratorium Jurusan Teknik Konversi Energi POLBAN. Parameter-parameter yang diuji meliputi: daya poros, konsumsi bahan bakar spesifik, effisiensi termal dan rasio udara-bahan bakar. Selain itu dilakukan juga pengujian kandungan emisi hasil pembakaran ecolu dari minyak jelantah (Altfett Methyl Ester/AME) dan hasil pembakaran bahan bakar solar, yang meliputi: emisi $\mathrm{NO}, \mathrm{CO}, \mathrm{HC}, \mathrm{SO}_{2}$ partikulat dan asap hitam

\section{HASIL DAN PEMBAHASAN}

\section{Karakteristik Ecolu}

Ecolu yang digunakan pada penelitian ini merupakan ecolu yang berasal dari minyak jelantah (minyak goreng bekas) yang diproduksi oleh PT. Bumi Energy Equatorial (BEE). Berdasarkan hasil pengujian karakteristik ecolu dan minyak solar yang dilakukan oleh PT. Bumi Energy Equatorial (BEE), yang meliputi: angka setan, densitas, sulfate ash, flash point, kandungan sulfur dan nilai kalor, yang ditunjukkan pada Tabel 1.

Dari Tabel 1 terlihat bahwa ecolu memiliki angka setan, densitas, dan flash point yang lebih tinggi dibandingkan dengan solar. Hal tersebut menunjukkan bahwa ecolu dapat meningkatkan kinerja mesin karena dengan angka cetane yang lebih tinggi menunjukkan peningkatan proses injeksi bahan bakar ke ruang bakar sehingga proses pembakaran menjadi lebih cepat (spontan). Sedangkan kekurangan dari ecolu adalah memiliki viskositas lebih kental sehingga memudahkan terjadinya penyumbatan pada saluran pompa injeksi.

Tabel 1 Data karakteristik ecolu dengan solar

\begin{tabular}{|c|c|c|}
\hline Karakteristik & Ecolu & Solar \\
\hline Cetane mumber & 62,4 & 42 \\
\hline Density g/ml & $0,868-0,879$ & 0,83 \\
\hline Sulfated Ash (\%wt) & 0 & Max 0.02 \\
\hline Flash Point & 211 & 70 \\
\hline Sulfur Content (\%wt) & $<0,0026$ & Max 50 \\
\hline LHV(KJ/kg) & 40.207 & 42.043 \\
\hline Viskositas & $1,9-6,0$ & $1,3-4,1$ \\
\hline
\end{tabular}

\section{Performansi Mesin Diesel}

\section{Daya Poros (Ne)}

Daya poros merupakan parameter utama dalam kineja suatu mesin. Daya poros adalah besarnya daya yang diperlukan untuk memutar poros. Semakin banyak konsumsi bahan bakar yang digunakan maka semakin besar pula daya yang dihasilkan. 


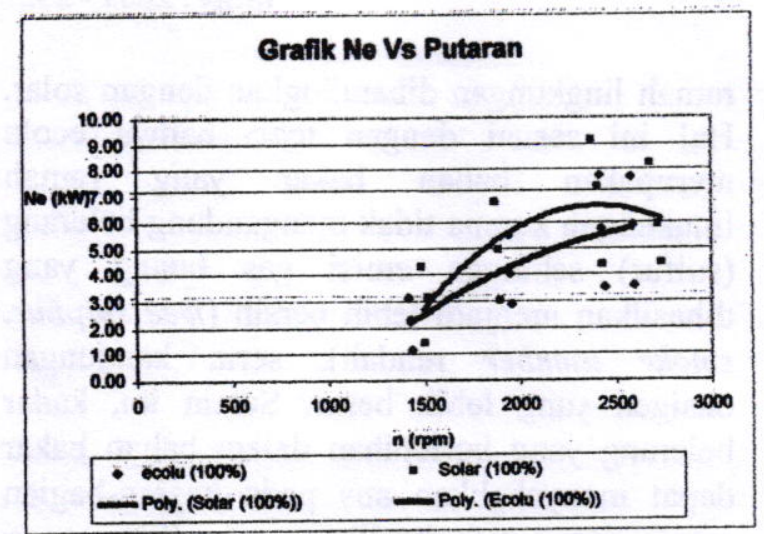

Gambar 1 Perbandingan daya poros $(\mathrm{Ne})$ terhadap putaran (n)

Pada Gambar 1 terlihat bahwa dengan meningkatnya putaran mesin makin meningkatkan daya poros yang dihasilkan, baik untuk bahan bakar solar maupun ecolu. Jika dibandingkan antara bahan ecolu dan solar pada putaran yang sama, daya poros ratarata yang dihasilkan oleh ecolu lebih rendah dibandingkan solar. Sebagai perbandingan terlihat pada putaran $2450 \mathrm{rpm}$, daya poros ecolu sebesar 3,52 KW sedangkan pada solar sebesar 4, $32 \mathrm{KW}$. Hal ini kemungkinan diakibatkan oleh nilai kalor ecolu yang lebih kecil $(40.207 \mathrm{KJ} / \mathrm{kg}$ ) dibandingkan nilai kalor solar (42.043 KJ/kg). Dari Gambar 1 juga terlihat bahwa pada saat putaran $2700 \mathrm{rpm}$ daya poros yang dihasilkan bahan bakar solar cenderung mengalami penurunan, sedangkan pada bahan bakar ecolu daya poros yang dihasilkan cenderung masih meningkat.

\section{Konsumsi Bahan Bakar Spesifik (Be)}

Konsumsi bahan bakar spesifik yaitu pemakaian bahan bakar untuk menghasilkan daya dari mesin diesel. Hal ini untuk menentukan sejauh mana keefisienan mesin diesel yang digunakan untuk mensuplai bahan bakar terhadap kerja yang dihasilkan. Agar efisiensi mesin menjadi semakin baik maka harus memiliki konsumsi bahan bakar spesifik yang rendah.

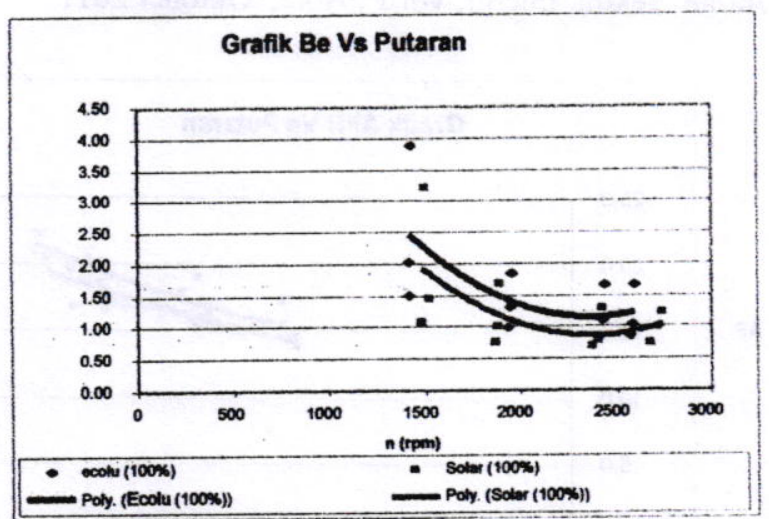

Gambar 2 Hubungan konsumsi bahan bakar spesifik (Be) Vs putaran (n)

Dari Gambar 2 terlihat bahwa konsumsi bahan bakar spesifik rata-rata pada ecolu mengalami penurunan begitu pula dengan solar. Jika dibandingkan antara ecolu dan solar pada putaran yang sama, rata-rata nilai konsumsi bahan bakar spesifik ecolu lebih tinggi dibanding solar. Sebagai perbandingan, pada putaran $2450 \mathrm{rpm}$ konsumsi bahan bakar spesifik ecolu sebesar $1,66 \mathrm{~kg} / \mathrm{KWh}$ sedangkan konsumsi bahan bakar spesifik solar sebesar $1,28 \mathrm{~kg} / \mathrm{KWh}$, hal ini kemungkinan disebabkan oleh nilai kalor ecolu yang lebih rendah dibanding solar. Dengan kata lain, penggunaan ecolu lebih boros dibanding solar.

\section{Air Fuel Ratio (AFR)}

Air Fuel Ratio merupakan perbandingan pemakaian udara dan bahan bakar untuk terjadinya proses pembakaran pada mesin. Pada Gambar 3 terlihat bahwa baik pada pengunaan ecolu maupun solar, makin besar putaran maka AFR nya makin meningkat. Tetapi bila dibandingkan antara ecolu dan solar pada putaran yang sama nilai AFR pada penggunaan bahan bakar ecolu lebih rendah dibanding solar. Dengan demikian penggunaan ecolu memerlukan lebih sedikit udara dibanding solar. Hal ini kemungkinan disebabkan oleh bahan bakar ecolu memiliki kandungan oksigen yang lebih banyak seperti halnya biodiesel. 


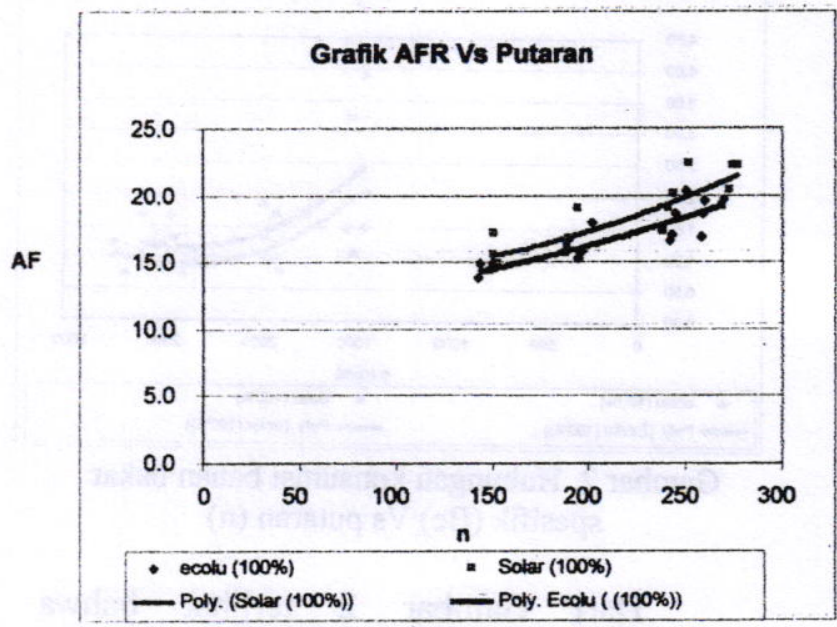

Gambar 3 Hubungan AFR vs putaran (n)

\section{Efisiensi Mekanik ( $\eta$ mekanik)}

Seperti yang terlihat pada Gambar 4, baik pada ecolu maupun solar terjadi peningkatan efisiensi mekanik dengan makin meningkatnya putaran mesin. Tetapi bila dibandingkan antara ecolu dan solar pada putaran yang sama, efisiensi mekanik pada bahan bakar ecolu lebih rendah dibanding solar. Sebagai perbandingan pada putaran $2450 \mathrm{rpm}$, efisiensi mekanik pada ecolu sebesar $8 \%$ sedangkan pada solar sebesar $10 \%$. Alasannya sama dengan di atas; karena nilai kalor ecolu lebih kecil dibanding solar.

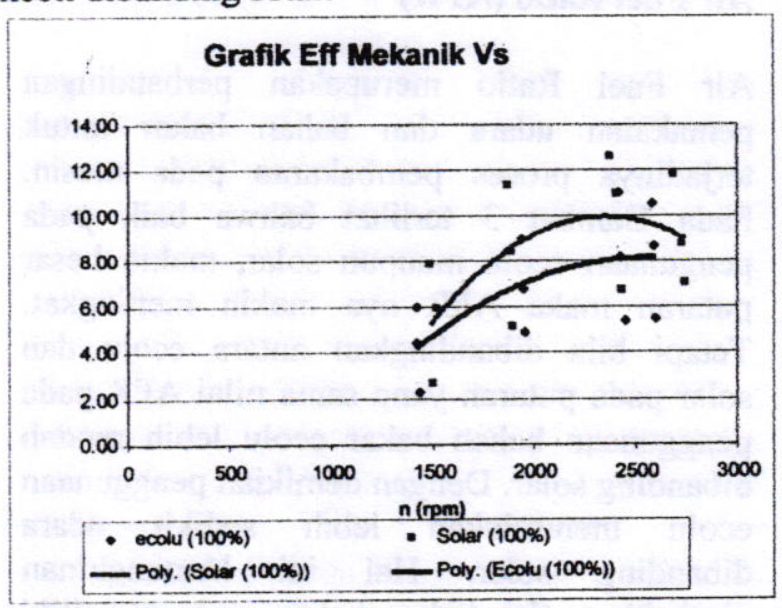

Gambar 4 Hubungan efisiensi mesin vs putaran (n)

\section{Emisi Gas Buang}

Hasil pengujian emisi gas buang yang dihasilkan oleh proses pembakaran bahan bakar ecolu dan solar ditunjukkan pada Tabel 4. Pada tabel tersebut terlihat bahwa emisi NO, $\mathrm{CO}, \mathrm{HC}, \mathrm{SO}_{2}$, asap hitam dan partikulat hasil pembakaran ecolu lebih rendah dari solar. Dengan demikian emisi gas buang ecolu lebih ramah lingkungan dibandingkan dengan solar. Hal ini sesuai dengan teori bahwa ecolu merupakan bahan bakar yang ramah lingkungan karena tidak mengandung belerang (sulfur) sehingga emisi gas buang yang dihasilkan menjadi lebih bersih (free sulphur, smoke number rendah), serta kandungan oksigen yang lebih besar. Selain itu, kadar belerang yang berlebihan dalam bahan bakar dapat menyebabkan aus pada bagian-bagian mesin dan menghasilkan gas SOx yang bersifat korosif dan sangat menggangu, sehingga dengan penggunaan ecolu yang bebas sulfur dapat menurunkan terjadinya aus dan korosif pada bagian mesin.

Tabel 2 Perbandingan emisi ecolu dan solar

\begin{tabular}{|l|l|l|}
\hline \multicolumn{1}{|c|}{$\begin{array}{c}\text { Emisi gas } \\
\text { buang }\end{array}$} & \multicolumn{1}{c|}{ Ecolu } & \multicolumn{1}{c|}{ Solar } \\
\hline Emisi NOx & $100 \mathrm{ppm}$ & $107 \mathrm{ppm}$ \\
\hline Emisi CO & $109 \mathrm{ppm}$ & $184 \mathrm{ppm}$ \\
\hline Emisi $\mathrm{HC}$ & $13,7 \mathrm{ppm}$ & $18,4 \mathrm{ppm}$ \\
\hline Emisi $\mathrm{SO}_{2}$ & $5,0 \mathrm{ppm}$ & $22,0 \mathrm{ppm}$ \\
\hline $\begin{array}{l}\text { Emisi partikulat/ } \\
\text { debu }\end{array}$ & $0,5 \%$ & $0,93 \%$ \\
\hline Asap hitam & $2 \%$ & $18 \%$ \\
\hline
\end{tabular}

\section{KESIMPULAN}

Ecolu memiliki bilangan cetana dan viskositas yang lebih tinggi, serta kadar sulfur dan LHV yang lebih rendah dibandingkan solar.

Performansi mesin diesel pada putaran yang sama $(2450 \mathrm{rpm})$ dengan menggunakan ecolu memiliki daya poros yang lebih rendah $(3,52$ $\mathrm{KW}$ ), konsumsi bahan bakar spesifik yang lebih besar $(1,66 \mathrm{~kg} / \mathrm{KWh})$ dan efisiensi mekanik yang lebih rendah (8\%) dibandingkan dengan bahan bakar solar yang berturut-turut 4, $32 \mathrm{KW} ; 1,28 \mathrm{~kg} / \mathrm{KWh}$ dan $10 \%$. Dengan demikian performansi mesin diesel berbahan bakar ecolu lebih rendah dibandingkan solar. Hal ini disebabkan oleh nilai kalor ecolu lebih rendah dibandingkan solar.

Pada umumnya, emisi gas buang yang dihasilkan oleh bahan bakar ecolu lebih baik dibandingkan solar, dengan emisi $\mathrm{NO}, \mathrm{CO}$, $\mathrm{HC}, \mathrm{SO}_{2}$, asap hitam dan partikulat yang lebih kecil. Dengan demikian ecolu merupakan bahan bakar alternatif yang lebih ramah lingkungan dibandingkan solar. 


\section{DAFTAR PUSATAKA}

Arismunandar, Wiranto, \& Koichi Tsuda, Motor Diesel Putaran Tinggi, Penerbit PT. Pradnya Paramita, Jakarta, 1975.

Arismunandar, Wiranto, Motor Bakar Torak, ITB, Bandung, 1988.

Hambali, Erliza, dkk, Teknologi BioEnergi, Penerbit Agro Media Pustaka, Bogor, 2007.

Seki H., Kikuchi H. Kubo T., Combustion and Performance Characteristics of HighSpeed Diesel Engine by Using BioMass fuels (in Japanese), BS Thesis of Kobe University of Mercantile Marine. (March 2001).

Sumadi, Sistem Kelistrikan \& Bahan Bakar Otomotif, Departemen Pendidikan \& Kebudayaan, Direktorat Pendidikan Menengah Kejuruan, Jakarta, 1979.
Syarief, Effendi, Minyak Nabati \&Biodiesel Sebagai Alternatif \& Gerakan, INSIST Press-LPTP, Yogyakarta, 2004.

Tina Mulya Gantina, Kartono, dan Maridjo, "Optimasi Tekanan Bahan Bakar Berkadar Biodiesel dalam Injektor Mesin Diesel", Journal Spektrum Teknologi, Vol. 15 No. 1 April 2008, Jurnal Penelitian dan pengembangan Teknologi Terapan, Politeknik Negeri Bandung, ISSN 1829-7587.

Zhang L. Matsumoto R., Ogata K., Ohde Y., "Combustion of Emulsion Fuel inHigh Speed Diesel Engines (in Japanese with English Abstract)", Journal of the Marine Engineering Society Japan, Vol. 23 No.4, pp.251-256, (April 1988). 